\title{
How to Progress from Discourse to Practice? A New Agenda for Change in Medical Schools into the Next Decade
}

\author{
José Lúcio Martins Machado ${ }^{1,2}$, Valéria Menezes P. Machado², Joaquim Edson Vieira ${ }^{3}$ \\ ${ }^{1}$ Faculdade de Medicina de Botucatu, Universidade Estadual Paulista (UNESP), Botucatu, Brasil \\ ${ }^{2}$ Universidade Cidade de São Paulo Medical School, São Paulo, Brasil \\ ${ }^{3}$ Faculdade de Medicina, Center for Development of Medical Education (CEDEM), Universidade de São Paulo, \\ São Paulo, Brasil \\ Email: joaquimev@usp.br
}

Received June 22 ${ }^{\text {nd }}$, 2012; revised July $26^{\text {th }}$, 2012; accepted August $5^{\text {th }}$, 2012

\begin{abstract}
In the context of medical school instruction, the segmented approach of a focus on specialties and excessive use of technology seem to hamper the development of the professional-patient relationship and an understanding of the ethics of this relationship. The real world presents complexities that require multiple approaches. Engagement in the community where health competence is developed allows extending the usefulness of what is learned. Health services are spaces where the relationship between theory and practice in health care are real and where the social role of the university can be revealed. Yet some competencies are still lacking and may require an explicit agenda to enact. Ten topics are presented for focus here: environmental awareness, involvement of students in medical school, social networks, interprofessional learning, new technologies for the management of care, virtual reality, working with errors, training in management for results, concept of leadership, and internationalization of schools. Potential barriers to this agenda are an underinvestment in ambulatory care infrastructure and community-based health care facilities, as well as in information technology offered at these facilities; an inflexible departmental culture; and an environment centered on a discipline-based medical curriculum.
\end{abstract}

Keywords: Guidelines; Education, Medical, Undergraduate; Problem-Based Learning; Professional Competence

\section{Introduction}

Modern scientific and technological developments have brought about deep changes in health practices that have mobilized large financial resources in different professional fields with training focused on specialization. However, the segmented approach of a focus on specialties and excessive use of technology seem to hamper the development of the professionalpatient relationship and an understanding of the ethics of this relationship. In parallel, medical schools take the same approach and promote a curriculum focused on targeting practices in hospitals of high complexity and multiple specialties. Resisting this view, international conferences such as the Alma Ata (1978) and others that followed have called for health practices that may support primary health care (PHC) instead, influencing trends in the training of health professionals (World Health Organization, 1978).

Issues like technology-driven medical care and hospital- and specialty-centered medical education are general in scope, likely affecting societies worldwide. Indeed, if the primary goal of undergraduate medical education is to produce students skilled in core medical competencies, then patient-centeredness needs a focus in parallel with learner-centeredness, and health care quality should be considered in parallel with educational quality as metrics of any medical education system (Hirsh et al., 2007).

How do we learn in the workplace? Learning by doing and reflecting on the work: “... competence consists in attributes displayed in the context of a carefully chosen set of realistic occupational tasks, which are of an appropriate level of gener- ality” (Hager and Gonczi, 1996). The real world presents complexities that require multiple approaches. Engagement in the community where health competence is developed allows extending the usefulness of what is learned. A wide range of skills associated with flexibility allows professionals to develop beyond “capability” (Fraser \& Greenhalg, 2001).

Knowing how to work as part of a team is essential at all levels of care, which involves fundamental concepts of interdisciplinary and multidisciplinary interaction. Health promotion and disease prevention have always been considered of low complexity, but the critical success factors are the combination of traditional approaches and the complexity of events, especially regarding their promotion (Feuerwerker, 2003).

The need to train professionals willing to take on the responsibility of caring for a diversity of needs and to use resources available in communities is imperative. Health services are privileged places for this purpose where the relationship between theory and practice in health comes to life and may confirm the social role of the university. The experience of the Brazilian health system and its reception of medical education present an interesting opportunity to monitor and learn from the development of learning with the practice of health care.

Although the literature in medical education emphasizes the primary health care and the focus during undergraduate directed towards patient and quality of care while performing as a team member, the complexities of "real world" health care challenges these prescriptions.

The objective of this hypothetic study was to propose an 
agenda in the field of medical education from experiences reported and related to the Brazilian experience with a national health system as well as with the implementation of an educational guideline for health education.

\section{Methods}

\section{An Agenda for the Decade}

A review of literature in the field of undergraduate medical education and the evaluation of educational experiences applied to Brazilian medical schools after the offering of a National Curriculum Guidelines in that country was applied. The literature search related to national experiences from those Guidelines included Brazilian journals in the field of medical education, from 2000 to 2012, and the national health system was considered as a base for the development of such guidelines.

In Brazil, two associated movements have resulted ultimately in efforts directed to both patient-centeredness and learnercenteredness: the organization of the health system and implementation of a national guideline for medical education. The first, related to health communitarian movements, is the National Health System - the SUS (for the Portuguese "Sistema Único de Saúde"), which relies on worker and user committee opinions in addition to those from technicians (Cornwall \& Shankland, 2008). Weaknesses and strengths have emerged in the process of implementing this system, alternating moments of significant advances with times of significant setback that have led to reassessment of its principles (Barnes \& Coelho, 2009).

The creation of the SUS and the representation of Brazilian society within it helped to boost the relationship between theory and practice, i.e., between health care and health education. In this environment, both governmental and associative initiatives led to the proposal of the National Curriculum GuidelinesDCN (Portuguese for "Diretrizes Curriculares Nacionais") in the year 2000, with important advances to promote communityoriented curricula and address community health needs (Resolução CNE/CES, 2001). The DCN allowed other methods of teaching and learning to be used for better incorporation across the accumulated knowledge. In this environment, new curriculum designs were outlined with active methods: Problem-based Learning, Projects-based Learning, and Learning Teams, each with its purposes.

Considering the advances in Brazilian medical schools in the last 10 years, as guided and encouraged by the DCN, an agenda for change in medical training for the second decade of the 21st century can be presented. This agenda prompts a progression from discourse to practice that could be embraced by undergraduate medical education institutions.

\section{Results}

1) Environmental Awareness. Combines policies of sustainability and preservation of life on the planet with the incorporation of new habits and health practices, including considerations of waste management, rational use of energy, and carbon deficits associated with health services and their impact on the health of the population (Pereira, 2007). Medical schools could embrace programs like the WHO city health profiles. Experiences already indicate that such programs provide an evidence base to inform health planning for a city, even though appropriate analyses for identifying inequalities within the city are still lacking. In these matters of identifying and mapping inequalities, engaged students could make the difference (Webster \& Lipp, 2009).

2) Student Involvement in Medical School: Medical educators around the world have linked three specific aspects to the recognition of excellence in education: evaluation (Assessment), student engagement (Engagement), and social responsibility and "accountability" to society (Accountability). The current schedule indicates a global medical education committed to social development, opening up spaces for the promotion of talents that unite expertise, training, a critical, reflective, and humanistic outlook, scientific curiosity, willingness, and the attitude of a lifelong learner (ASPIRE, 2011). In fact, some experiences set the stage for medical training, including the importance of understanding the philosophy of service learning and time for reflection (Elam et al., 2002).

3) Social Networks produce significant sites of learning, whether formal school spaces or informal learning experiences. The "Canadian Council of Learning" defines the multiplicity of spaces and situations such as mixtures of "unlimited dimensions of learning" and points out the need to register these situations and access evidence evaluation with qualitative and quantitative research. The popularity of social networks highlights the need to incorporate them as a teaching medium and to research their educational potential (Marti, 2010). Although these networks are relatively new, some investigations already suggest the potential that social networks have for disseminating innovations in health service delivery and organization (Jippes et al., 2010).

4) Interprofessional Learning requires integration of experiences among medicine and other professions, right from the beginning. The "Network towards Unity for Health"

(http://www.the-networktufh.org/home/index.asp) is a network that has contributed to this view, using the concept that interprofessional education occurs when "one or more professions learn with, for, and about each one, to improve collaboration and quality of care." Versatile and flexible curricula are based on the experience of Bologna's interdisciplinary bachelor's process, the medical schools of Canada, and the formation of the American "College” (Almeida Filho, 2008). However, interprofessional learning is not an easy task, considering the suggested three levels of action that must be incorporated: individual, group (faculty), and institution, all to influence health and educational practices (Ho et al., 2008).

5) New Technologies for the Management of Care. Developing technologies for the management of care that include expanded clinical aspects (patient accountability), construction of lines of care (organization of work for the integral and humanized assistance-continuity of care, acceptance, commitment, accountability, and problem solving), matrices (enabling interconnection among care services in primary, secondary, and tertiary health care), and shared construction of individual therapeutic projects (a therapeutic single subject or individual's involvement in the community as a result of interaction with an interdisciplinary health team) (Campos et al., 2006).

6) Virtual Reality, Robotics, Artificial Intelligence in telemedicine and graduate training in health as a replacement for the set of practices that may go into disuse. Some examples are the teaching of anatomy, pathology, and surgical skills in undergraduate medical education, with difficulties that arise from cadaver availability and the pressure from animal defense and protection movements (Machado, 2010). These two items are 
directly or indirectly related to simulation, and there seems to be no question of whether medical simulation is a critical component of training and certification (Gordon, 2012).

7) Working with Reflection and Error in the evaluations of medical students by using the tools that encourage reflection on daily practice. Portfolio narratives from human and personal experiences during medical education are good examples. The systematization of recording practical aims makes possible knowledge assessment, questioning of conflicts, and generation of reflections. The reflection on errors involves values of ethics, transparency, autonomy, and responsibility. The school must provide a "sheltered environment" where error is observed, and the simulations, of either high or low-fidelity mannequin, have been gaining ground among the most successful environments in this field (Aranaz et al., 2008).

8) Training in Management for Results. Regardless of the chosen specialty, actions must be proactive and direct to resolve collective as well as individual care. It should include health promotion, prevention of risks and diseases, and rehabilitation of patients and the communities. In contrast to the apparent broad spectrum of competence and performance, it should focus on primary care and emergency care of low and medium complexity. Performance evaluations should be promoted not only for purposes of certification and recertification training but also to promote institutional self-knowledge and its graduates (Vecina Neto \& Malik, 2011).

9) Developing the Concept of Leadership as a competence required for a medical professional. Issues include globalization, climate change, digital literacy, the balance of individualism and team actions, and finally the ability to manage student diversity and the approach of teachers who encounter various habits, cultures, and languages (Morin, 2000). Even though leadership is not a task simply related to identifying high-potential individuals, their strengths, and the provision of didactic and experiential learning (Wolf et al., 2005), it seems that immersion in the community would provide a rich and complex experience.

10) The Internationalization of Schools and Medical Education aims at universal characteristics: quality, equity, relevance, innovation, and appropriate use of resources should be improved at schools and during the practice of medical training. In this context, the increasing mobility of health professionals and patients from different countries may present a need for new training profiles and curricula that provide mobility for students to experience different environments and contexts. International certification and accreditation takes on new meaning for social engagement (AAMC-Association of American Medical Colleges, 2011; Biggs, 2010; Snadden et al., 2011; Boelen \& Woollard, 2011). Perhaps even more challenging would be to consider this engagement as an effort to set up collaboration between a number of schools in different countries, bringing a global context rather than the context of a single country to the medical education teaching and learning environment (Harden, 2006).

\section{Discussion}

The health human resources community in Brazil has a history of a partnership between Pan-American Health Organization (PAHO) and the Ministry of Health that has allowed the development of projects such as Teaching Care Integration (IDA, for Portuguese "Integração Docente-Assistencial”). Its premise was to develop medical training and health care in the same field, combining theory and practice. Individual and institutional resistance within universities and a short maturity period of the SUS as a field of practice limited these projects (Marsiglia, 1995); however, the IDA paved the way for a new program supported by the Kellogg Foundation, the "UNI Program-A New Initiative in the Education of Health Professionals, Union with the Community” (1991-1997), focused on improving the training of health professionals. A key differentiator for both projects was involving the community with leadership training and participation within its own management (Machado et al., 1997).

In the decade after the DCN was established, medical schools followed and adapted to the DCN, exposing themselves, instructors, and students to the external environments of the real health system. It seemed they could indeed engage in real-world experience as a way to explore the advancements in science and technology with the intention to achieve excellence. But what, in fact, is excellence?

The answer to this question lies in the "Agenda de Salud para las Américas” 2008-2017 from PAHO/World Health Organization (WHO), which focuses on promoting the progress of medical education. This agenda, involving countries of the Americas and the Caribbean, aims to improve health indicators by $15 \%$ by 2015 . The basis for this action is the sharing of new teaching practices aimed at PHC and the development of collaboration and documentation (Organización Panamericana de la Salud, 2007).

All of these efforts indicate the need to train professionals willing to take on the responsibility of caring for a diversity of needs and to use resources available in communities. Health services are privileged places for this purpose where the relationship between theory and practice in health comes to life and may confirm the social role of the university. The experience of the Brazilian health system and its reception of medical education present an interesting opportunity to monitor and learn from the development of learning with the practice of health care.

How to "recognize health as a right, and act to ensure comprehensive health care" is a responsibility that demands complex educational resources, located beyond the classroom. In the SUS, the Family Health Teams create fertile ground for the development of comprehensive care and for Continuing Education in Health. To look critically at the contextual situation and be able to plan health actions are also flagged by the DCN. The professionalization of teaching is a powerful strategy used by some schools as well as the continuing education program in place for health professionals (Machado et al., 2011).

In addition, the objective "to know the principles of scientific methodology" indicates that the student must be a builder of critical knowledge of relevant information. The application of the DCN implies changes in the structure and organization of the Brazilian university in its own environment, which asks for the listening and reflection of qualified peers, institutional partners, and students (Feuerwerker \& Sena, 2002; Bowe et al., 2003).

The Brazilian DCN suggests the necessary skills as follows: 1 ) Health care at different levels because these levels are not readily identified in the work processes; 2) Decision-making because competence requires professionals who have skills and work out systematization and evidence; 3) Communication skills that involve multidisciplinary knowledge and interactions based on codes that should be understood and recognized as familiar and invite participation; 4) Leadership, the commitment to and re- 
sponsibility for the skills already described; 5) Administration and management because they are not equitable for all health professions; and 6) Continuing education, or the ability to learn how to learn, which can be achieved through specific teaching strategies.

The DCN also established specific skills for scientific and technical issues: proficiency in medical history, physical examination, interpretation of laboratory tests, clinical reasoning, and therapeutics. There are difficulties, however, such as when to consider the epidemiological criteria for the topics covered in the training curriculum (Machado et al., 2012).

Some competencies are lacking, and may need the establishment of a environment where to develop them: the competence of working in primary care because most medical professionals/teachers were trained in a hospital-centered model school; the competence of acting as an agent of social change because there is limited experience in exercising politics in the sense of citizenship; and the promotion of a healthy lifestyle, although it is a skill not so distant from the practice of health education courses and services, considering that the actions related to health promotion are more accepted by the health services as something that does not disturb their routine (Cotta et al., 2007).

We believe the majority of potential barriers to this agenda could be related to those of any new educational approach in general (Hirsh et al., 2007). The two most important barriers related to health care are probably underinvestment in 1) ambulatory care infrastructure as well as in community-based health care facilities directed to promote a learning environment and 2) in information technology offered at these facilities (ambulatory and community). In addition, the almost inflexible departmental culture, mostly related to an environment where the medical curriculum is discipline based, could impair progress toward an improved understanding and compromise for a patient-centered education process. A simple strategy, like visiting families in underserved areas, has helped medical undergraduate students to acquire capacities in identifying social and local health realities and understanding the Family Health Program, the PHC structure, and the national health system (Vieira et al., 2007).

\section{REFERENCES}

AAMC-Association of American Medical Colleges (2011). Global health learning opportunities. URL (last checked 28 November 2011). http://www.aamc.org/students/medstudents/ghlo/

Almeida Filho, N. (2008). Modelo de educação superior: Modelo norteamericano. In Santos, B. S., Almeida Filho, N. (Eds.), A universidade no século XXI: Para uma universidade nova. Coimbra: Almedina.

Aranaz, J. M., Aibar, C., Vitaller, J., \& Mira, J. J. (2008). Gestión sanitária: Calidad y seguridade de los pacientes. Madrid: Diaz de Santos.

ASPIRE (2011). Medical school programme for international recognition of excellence in education. URL (last checked 28 November 2011). http://www.amee.org/documents/ASPIRE.pdf

Barnes, M., \& Coelho, V. S. (2009). Social participation in health in Brazil and England: Inclusion, representation and authority. Health Expectations, 12, 226-236. doi:10.1111/j.1369-7625.2009.00563.x

Biggs, J. (2010). La enseñanza de los estudiantes internacionales. In Biggs, J. (Ed.), Calidad del aprendizaje universitário. Madrid: Narcea.

Boelen, C., \& Woollard, R. (2011). Consenso global sobre la responsabilidade social de las facultades de medicina. Educación Medica, 14, 7-14.

Bowe, C. M., Lahey, L., Kegan, R., \& Armstrong, E. (2003). Ques- tioning the "big assumptions". Part II: Recognizing organizational contradictions that impede institutional change. Medical Education, 37, 723-733. doi:10.1046/j.1365-2923.2003.01580.x

Campos, G. W. S., Minayo, M. C. S., Akerman, M., Drumond Jr., M., \& Carvalho, Y. M. (2006). Tratado de saúde coletiva. São Paulo: Hucitec.

Cornwall, A., \& Shankland, A. (2008). Engaging citizens: Lessons from building Brazil's national health system. Social Science \& Medicine, 66, 2173-2184. doi:10.1016/j.socscimed.2008.01.038

Cotta, R. M. M., Gomes, A. P., Maia, T. M., Magalhães, K. A., Marques, E. S., \& Siqueira-Batista, R. (2007). Pobreza, injustiça, e desigualdade social: Repensando a formação de Profissionais de Saúde. Revista Brasileira de Educação Médica, 31, 278-286. doi:10.1590/S0100-55022007000300010

Elam, C. L., Musick, D. W., Sauer, M. J., \& Skelton, J. (2002). How we implemented a service-learning elective. Medical Teacher, 24, 249253. doi:10.1080/01421590220134079

Feuerwerker, L. C. M. (2003). Educação dos profissionais de Saúde hoje problemas, desafios, perspectivas e as propostas do ministério da saúde. Revista da ABENO, 3, 24-27.

Feuerwerker, L. C. M., \& Sena, R. R. (2002). A contribuição ao movimento de mudança na formação profissional em saúde: Uma avaliação das experiências UNI. Interface-Comunicação, Saúde e Educação, 6, 37-50. doi:10.1590/S1414-32832002000100004

Fraser, S. W., \& Greenhalg, T. (2001). Coping with complexity: Educating for capability. British Medical Journal, 323, 799-803. doi:10.1136/bmj.323.7316.799

Gordon, J. A. (2012). As accessible as a book on a library shelf: The imperative of routine simulation in modern health care. Chest, 141, 12-16. doi:10.1378/chest.11-0571

Hager, P., \& Gonczi, A. (1996). What is competence? Medical Teacher, 18, 15-18. doi:10.3109/01421599609040255

Harden, R. M. (2006). International medical education and future directions: A global perspective. Academic Medicine, 81, S22-S29. doi:10.1097/01.ACM.0000243411.19573.58

Hirsh, D. A., Ogur, B., Thibault, G., \& Cox, M. (2007). “Continuity” as an organizing principle for clinical education reform. The New England Journal of Medicine, 356, 858-866. doi:10.1056/NEJMsb061660

Ho, K., Jarvis-Selinger, S., Borduas, F., Frank, B., Hall, P., Handfield-Jones, R., Hardwick, D. F., Lockyer, J., Sinclair, D., Lauscher, H. N., Ferdinands, L., MacLeod, A., Robitaille, M. A., \& Rouleau, M. (2008). Making interprofessional education work: The strategic roles of the academy. Academic Medicine, 83, 934-940. doi:10.1097/ACM.0b013e3181850a75

Jippes, E., Achterkamp, M. C., Brand, P. L., Kiewiet, D. J., Pols, J., \& Van Engelen, J. M. (2010). Disseminating educational innovations in health care practice: Training versus social networks. Social Science \& Medicine, 70, 1509-1517. doi:10.1016/j.socscimed.2009.12.035

Machado, J. L., CaldasJr., A. L., \& Bertoncello, N. M. F. (1997). Uma nova inciativa na formação de profissionais de saúde. InterfaceComunicação, Saúde e Educação, 1, 147-156. doi:10.1590/S1414-32831997000200011

Machado, J. L. M. (2010). Habilidades cirúrgicas no contexto da educação médica inovadora. Manual de habilidades cirúrgicas na graduação em medicina. Belo Horizonte: Medvance.

Machado, J. L. M., Machado, V. M., \& Vieira, J. E. (2011). Formação e seleção de docentes para currículos inovadores na graduação em saúde. Revista Brasileira de Educação Médica, 35, 326-333. doi:10.1590/S0100-55022011000300005

Machado, J. L. M., Souza, S. R. P., Brenna, S. M. F., Pose, R. A., Bollela, V. R., \& Vieira, J. E. (2012). Use of epidemiological data as the basis for developing a medical curriculum. São Paulo Medical Journal, 130, 109-114. doi:10.1590/S1516-31802012000200007

Marsiglia, R. G. (1995). Relação ensino/serviços: dez anos de integração docente-Assistencial (IDA) no Brasil. São Paulo: Hucitec.

Martí, M. C. (2010). Las redes sociales para enseñar y aprender. Reflexiones pedagógicas básicas. In: L. C. Quintero, \& J. C. Almenara (Eds.), Aprendizaje con redes sociales. Tejidos educativos para los nuevos entornos. Sevilla: MAD.

Morin, E. (2000). Saberes globais e saberes locais: O olhar transdisci- 


\section{J. L. M. MACHADO ET AL.}

plinar. Rio de Janeiro: Garamond.

Organización Panamericana de la Salud (2007). Agenda de Salud para las Americas-2008-2017. URL (last checked 28 November 2011). http://www.ops.org.bo/textocompleto/iagenda32191.pdf

Pereira, D. C. P. (2007). Nova educação na nova ciência para a nova sociedade. Fundamentos de uma pedagogia científica contemporânea. Porto: Ed. UP.

Resolução CNE/CES (2001). Institui diretrizes curriculares nacionais do curso de graduação em medicina. URL (last checked 28 November 2011). http://portal.mec.gov.br/cne/arquivos/pdf/CES04.pdf

Snadden, D., Bates, J., Burns, P., Casiro, O., Hays, R., Hunt, D., \& Towle, A. (2011). Developing a medical school: Expansion of medical student capacity in new locations: AMEE guide no. 55. Medical Teacher, 33, 518-529. doi:10.3109/0142159X.2011.564681

Vecina Neto, G., \& Malik, A. M. (2011). Gestão em saúde. Rio de Janeiro: Guanabara Koogan.
Vieira, J. E., Elias, P. E. M., Benseñor, I. J. M., \& Grisi, S. J. E. (2007) Implementation of the discipline basic care at the Faculty of Medicine of the University of São Paulo [Portuguese]. Revista Brasileira de Educação Médica, 31, 236-244. doi:10.1590/S0100-55022007000300006

Webster, P., \& Lipp, A. (2009). The evolution of the WHO city health profiles: A content review. Health Promotion International, 24, i56i63. doi:10.1093/heapro/dap055

Wolf, G., Bradle, J., \& Nelson, G. (2005). Bridging the strategic leadership gap: A model program for transformational change. Journal of Nursing Administration, 35, 54-60.

World Health Organization (1978). Declaration of Alma-Ata. URL (last checked 28 November 2011).

http://www.who.int/publications/almaata_declaration_en.pdf 